\title{
ANALISIS FLUKTUASI PEMAKAIAN AIR PDAM TIRTA MOEDAL KOTA SEMARANG WILAYAH STUDI DMA TEJOSARI DAN MEGA BUKIT MAS
}

\author{
Riski Adyan Prasasti ${ }^{1 *}$, Ganjar Samudro \\ ${ }^{1}$ )Departemen Teknik Lingkungan, Fakultas Teknik, Universitas Diponegoro \\ JI. Prof. Soedarto, SH, Kampus Undip Tembalang, Semarang, Indonesia 50275 \\ e-mail: riskiadyan23@gmail.com
}

\begin{abstract}
Abstrak
Setiap wilayah memiliki pemakaian air yang berbeda-beda pada setiap jam dan hari sebagai fluktuasi pemakaian air. Dengan pemakaian air yang berbeda-beda, maka sistem penyediaan air membutuhkan suplai air yang berbeda pula, sesuai dengan fluktuasi pemakaian air tiap wilayah. Dengan mengetahui fluktuasi pemakaian air, maka operasi sistem penyediaan air minum dapat direncanakan untuk memenuhi kebutuhan air. Penelitian ini bertujuan untuk merencanakan operasional sistem penyediaan air secara efisien berdasarkan fluktuasi pemakaian air. Dalam penelitian ini, wilayah kajian adalah DMA Tejosari dan Mega Bukit Mas, PDAM Tirta Moedal Kota Semarang Cabang Semarang Selatan. Pengambilan data didapatkan dari pembacaan meter induk di wilayah studi selama tujuh hari. Hasil penelitian ini didapatkan bahwa jam puncak penggunaan air berada pada jam pertama air mengalir, dengan faktor jam puncak secara berturut-turut adalah 1,64 dan 1,68. Sedangkan untuk faktor harian maksimum kedua DMA sebesar 1,25. Selain untuk mengetahui faktor jam puncak dan harian maksimum, pembacaan meter induk juga bertujuan untuk mengetahui volume reservoir yang dibutuhkan yaitu sebesar $628,25 \mathrm{~m}^{3}$ untuk DMA Tejosari.
\end{abstract}

Kata kunci: fluktuasi pemakaian air; sistem penyediaan air minum

\begin{abstract}
Each region has different water usage every hour and day as water usage fluctuation. With different water uses, the water supply system requires a different water supply, according to the fluctuations in water usage in each region. By knowing the fluctuations in water usage, the operation of water supply system can be planned to fill water needs. This study aims to plan the operation of the water supply system efficiently based on fluctuations in water use. In this study, the study area are Tejosari and Mega Bukit Mas DMA, PDAM Tirta Moedal Semarang City South Semarang Branch. Data collection was obtained from main meter reading in the study area for seven days. The results of this study found that the peak hours of water use were in the first hour of flowing water, with the peak hour factors respectively 1.64 and 1.68. Whereas for the maximum daily factor of both DMA is 1.25. In addition to knowing the peak hour and day maximum, reading the main meter also aims to determine the required reservoir volume, there is $628.25 \mathrm{~m}^{3}$ for the Tejosari DMA.
\end{abstract}

Keywords: water usage fluctuation; water suply system

\section{Pendahuluan}

Air sangat penting bagi kehidupan manusia, namun sudah tidak lagi menjadi kebutuhan dasar essensial, air merupakan kebutuhan untuk berbagai aktivitas kehidupan seperti MCK, irigasi, pembangkit listrik dan sebagainya (Mangkoedihardjo dan Samudro, 2012). Oleh karena itu, sistem penyediaan air minum harus memperhatikan aspek-aspek yang sangat berpengaruh yaitu kualitas, kontinuitas, dan kuantitas (K3) (Siregar dan Mulia, 2013). Pemenuhan kebutuhan air didapat berdasarkan jumlah penduduk yang dilayani, kebutuhan air domestik dan non domestik, kobocoran air, dan kebutuhan air pemadam kebakaran (Hidayat dkk,2014). Meningkatnya pemenuhan kebutuhan air juga bisa dibarengi dengan upaya 
pengembangan jaringan distribusi air, sehingga diperlukan data berupa pemakaian air pada jam-jam puncak (peak hour) dan pada hari-hari tertentu-tertentu (maximum day) (Syahputra,2018). Semakin berkembangnya jaringan PAM, maka faktor lain yang akan muncul yaitu kehilangan air, agar pemenuhan kebutuhan air bisa maksimal, maka hal yang bisa dilakukan adalah meminimalkan tingkat kehilangan air (Farleydkk, 2008 dalam Saparina,2017).

PDAM Tirta Moedal Kota Semarang merupakan instansi penyedia jasa air minum yang melayani kebutuhan air bagi masyarakat Kota Semarang, menurut data PDAM TirtaMoedal Kota Semarang bulan September 2017, jumlah pelanggan sebanyak 168.513 SR. Dalam proses penyaluran air minum, PDAM Tirta Moedal Kota Semarang membagi dalam lima cabang pelayanan, salah satunya yaitu Semarang Selatan dengan jumlah pelanggan sebanyak 28.108 SR. PDAM Tirta Moedal Kota Semarang mendapat pasokan air melalui 14 sumur artetis, dan tiga mata air yaitu Sumber Kalidoh, Moedal,dan Lawang. DMA mega Bukit Mas mendapatkan pasokan dari Sumber Kalidoh.

Penyaluran air menuju DMA Tejosari da Mega Bukit Mas menggunakan cara gravitasi pada sistem transmisim, sedangkan untuk sistem distribusi menggunakan cara perpompaan, dan masih menggunakan sistem bergilir dimana kedua DMA tersebut mendapat pasokan air setiap dua hari sekali dengan waktu pelayanan 17 jam. Pemakaian air setiap harinya akan berbeda, sehingga dapat terjadi fluktuasi pola pemakaian air, kemudian memunculkan jam puncak dan jam minimum pemakaian air pada sistem. Dengan mengetahui fluktuasi pemakaian air, maka sistem operasi penyediaan air minum di PDAM Tirta Moedal Kota Semarang Cabang Semarang Selatan akan lebih efisien.

\section{Metodologi Penelitian}

Wilayah studi mengambil lokasi DMA Mega Bukit Mas yang merupakan area yang dilayani oleh PDAM Tirta Moedal Cabang Semarang Selatan. Pengamatan dilakukan dengan cara membaca meter induk di DMA Mega Bukit Mas selama tujuh periode pengaliran, dimulai pada Sabtu, 9 Desember 2017 sampai Jumat, 22 Desember 2017. Pembacaan meter induk dilakukan setiap tiga jam sekali, dimulai pukul 19.00 hingga pukul 10.00 .
Selama penelitian, peralatan yang diperlukan yaitu: Meter air, alat tulis, kamera handphone dan kertas untuk mencatat hasil meter induk. Sedangkan, cara pengambilan data untuk mengetahui pemakaian air adalah sebagai berikut:

1. Memastikan bahwa air yang mengalir ke DMA Mega Bukit Mas melewati meter induk 2. Mendokumentasikan posisi angka pada meter induk, lalu mencatat nya pada kertas yang telah disiapkan. Mendokumentasikan posisi angka meter induk berfungsi sebagai back up data apabila terjadi sesuatu.

3. Menghitung debit pemakaian air setiap tiga jam sampai dengan 16 jam. Perhitungan debit pemakaian air dapat menggunakan rumus berikut:

$\mathrm{Q}=($ stand awal - stand akhir)

Dimana :

Q : debit pemakaian air ( $\mathrm{m}^{3} /$ tiga jam)

Stand akhir : angka pada meter air pada jam pembacaan ke-2

Stand awal : angka pada meter air pada jam pembacaan ke-1

Dari hasil pengamatan, akan didapatkan penggunaan air setiap tiga jam sekali selama tujuh periode pengaliran. Sehingga, dapat diketahui pula faktor jam puncak dan faktor harian maksimum dengan rumus berikut:

Faktor jam puncak = $\frac{\text { Debit jam puncak }}{\text { Debit rata-rata }}(2)$

Faktor Harian Maksimum = Debit Maksimum

$\overline{\text { Debit Rata-Rata }}$

\section{Hasil dan Pembahasan}

Dalam perencanaan suatu sistem penyediaan air bersih, dikenal istilah fluktuasi pemakaian air. Data tentang fluktuasi pemakaian air bersih ini merupakan data yang sangat penting. Hal ini dikarenakan kapasitas sistem harus mencukupi untuk mengatasi kebutuhan air saat hari maksimum maupun pada jam puncak. Data fluktuasi pemakaian air bersih juga dapat digunakan untuk menghitung kapasitas dari bak penampung atau reservoir ( Jujubandung, 2012). Pembacaan meter induk berguna untuk menghitung kebutuhan air bersih sehingga didapatkan angka faktor pengali tertentu yaitu faktor harian maksimum (fhm) dan faktor jam puncak (fp). 
Tabel 1.Pembacaan Meter Induk DMA Tejosari dan DMA Mega Bukit Mas

\begin{tabular}{|c|c|c|c|c|c|c|}
\hline \multirow{2}{*}{ Periode } & \multirow{2}{*}{ Hari dan Tanggal } & \multirow{2}{*}{ Waktu } & \multicolumn{2}{|c|}{ DMA Tejosari } & \multicolumn{2}{|c|}{ DMA Mega Bukit Mas } \\
\hline & & & Kubikasi (m3) & Debit (I/detik) & Kubikasi (m3) & Debit (I/detik) \\
\hline \multirow[t]{6}{*}{1} & Sabtu, 9 Desember 2017 & 19.00 & & & & - \\
\hline & & 22.00 & 340 & 94,4 & 564 & 156,67 \\
\hline & Minggu, 10 Desember 2017 & 01.00 & 128 & 35,6 & 1087,2 & 302,00 \\
\hline & & 04.00 & 229 & 63,6 & 1195 & 331,94 \\
\hline & & 07.00 & 103 & 28,6 & 322 & 89,44 \\
\hline & & 10.00 & 278 & 77,2 & 796 & 221,11 \\
\hline \multirow[t]{6}{*}{2} & Senin, 11 Desember 2017 & 19.00 & & - & & \\
\hline & & 22.00 & 295 & 81,9 & 2049 & 569,17 \\
\hline & Selasa, 12 Desember 2017 & 01.00 & 218 & 60,6 & 1259 & 349,72 \\
\hline & & 04.00 & 169 & 46,9 & 1364 & 378,89 \\
\hline & & 07.00 & 31 & 8,6 & 545 & 151,39 \\
\hline & & 10.00 & 187 & 51,9 & 870 & 241,67 \\
\hline \multirow[t]{6}{*}{3} & Rabu, 13 Desember 2017 & 19.00 & & - & & - \\
\hline & & 22.00 & 201 & 55,8 & 1502 & 417,22 \\
\hline & Kamis, 14 Desember 2017 & 01.00 & 117 & 32,5 & 1008 & 280,00 \\
\hline & & 04.00 & 211 & 58,6 & 1305 & 362,50 \\
\hline & & 07.00 & 240 & 66,7 & 534 & 148,33 \\
\hline & & 10.00 & 235 & 65,3 & 903 & 250,83 \\
\hline \multirow[t]{6}{*}{4} & Jumat, 15 Desember 2017 & 19.00 & & - & & - \\
\hline & & 22.00 & 256 & 71,1 & 1971 & 547,50 \\
\hline & Sabtu, 16 Desember 2017 & 01.00 & 101 & 28,1 & 1504 & 417,78 \\
\hline & & 04.00 & 180 & 50,0 & 458 & 127,22 \\
\hline & & 07.00 & 213 & 59,2 & 1592 & 442,22 \\
\hline & & 10.00 & 336 & 93,3 & 779 & 216,39 \\
\hline
\end{tabular}




\begin{tabular}{|c|c|c|c|c|c|c|}
\hline \multirow{2}{*}{ Periode } & \multirow{2}{*}{ Hari dan Tanggal } & \multirow{2}{*}{ Waktu } & \multicolumn{2}{|c|}{ DMA Tejosari } & \multicolumn{2}{|c|}{ DMA Mega Bukit Mas } \\
\hline & & & Kubikasi (m3) & Debit (I/detik) & Kubikasi (m3) & Debit (I/detik) \\
\hline \multirow[t]{6}{*}{5} & Minggu, 17 Desember 2017 & 19.00 & & - & & \\
\hline & & 22.00 & 193 & 53,6 & 1818 & 505,00 \\
\hline & Senin, 18 Desember 2017 & 01.00 & 63 & 17,5 & 875 & 243,06 \\
\hline & & 04.00 & 109 & 30,3 & 1181 & 328,06 \\
\hline & & 07.00 & 284 & 78,9 & 606 & 168,33 \\
\hline & & 10.00 & 236 & 65,6 & 967 & 268,61 \\
\hline \multirow[t]{6}{*}{6} & Selasa, 19 Desember 2017 & 19.00 & & - & & - \\
\hline & & 22.00 & 256 & 71,1 & 2027 & 563,06 \\
\hline & Rabu, 20 Desember 2017 & 01.00 & 62 & 17,2 & 863 & 239,72 \\
\hline & & 04.00 & 135 & 37,5 & 1286 & 357,22 \\
\hline & & 07.00 & 172 & 47,8 & 1748 & 485,56 \\
\hline & & 10.00 & 235 & 65,3 & 1393 & 386,94 \\
\hline \multirow[t]{6}{*}{7} & Kamis, 21 Desember 2017 & 19.00 & & - & & - \\
\hline & & 22.00 & 250 & 69,4 & 2524 & 701,11 \\
\hline & Jumat, 22 Desember 2017 & 01.00 & 267 & 74,2 & 813 & 225,83 \\
\hline & & 04.00 & 175 & 48,6 & 1127 & 313,06 \\
\hline & & 07.00 & 287 & 79,7 & 3883 & 1078,61 \\
\hline & & 10.00 & 289 & 80,3 & 2748 & 763,33 \\
\hline \multicolumn{3}{|c|}{$\begin{array}{l}\text { Dari data yang didapat melalui pembacaan meter induk maka dapat } \\
\text { diketahui debit total, debit rata-rata, debit jam puncak, dan faktor jam } \\
\text { puncak. Berikut adalah perhitungan debit dan faktor jam puncak kedua } \\
\text { DMA: } \\
\text { Menurut Hidayat, dkk (2013) dalam perencanaan dimensi pipa harus } \\
\text { memenuhi ketentuan teknis yaitu pipa harus direncanakan utuk } \\
\text { mengalirkan debit maksimum harian. Dijelaskan pula dalam PERMEN } \\
\text { PU No.18 Tahun } 2007 \text { Penyelenggaraan Pengembangan Sistem } \\
\text { Penyediaan Air Minum bahwa unit air baku direncanakan berdasarkan } \\
\text { kebutuhan hari puncak yang besarnya berkisar } 130 \% \text { dari kebutuhan } \\
\text { rata-rata sedangkan untuk unit produksi, besarnya berkisar } 120 \% \text { dari } \\
\text { kebutuhan rata-rata. Unit air baku transmisi dan pengolahan } \\
\text { menggunakan Qmax dikarenakan pengolahan dilakukan selama sehari } \\
\text { atau } 24 \text { jam, sehingga harus dapat memenuhi kebutuhan harian }\end{array}$} & \multicolumn{4}{|c|}{$\begin{array}{l}\text { maksimum atau Q max dimana kebuthan paling besar pada suatu har } \\
\text { dalam setahun, seperti Hari Raya Idul Fitri (Primadi, Gantara, } 2015 \\
\text { dalam Jujubandung, 2012). Selain itu, Primadi,Gantara (2015) dalam } \\
\text { Jujubandung (2012) juga menjelaskan bahwa perencanaan pipa } \\
\text { distribusi biasanya menggunakan kebutuhan jam puncak atau } \\
\text { Qpeaksebagai dasar perencanaan pipa. Hal ini dikarenakan } \\
\text { penggunaan pada satu hari berfluktuasi atau berubah-ubar } \\
\text { setiapjamnya (misalnya pada pemakaian banyak dipagi hari untuk } \\
\text { beribadah dan mandi pagi) sehingga harus dapat memenuhi kebutuhar } \\
\text { yang ada pada jam-jam pemakaian debit paling besar dalam satu hari } \\
\text { Diperjelas pula dalam PERMEN PU No.18 Tahun } 2007 \\
\text { Penyelenggaraan Pengembangan Sistem Penyediaan Air Minum } \\
\text { bahwa unit distribusi direncanakan berdasarkan kebutuhan jam puncak } \\
\text { yang besarnya berkisar } 115 \%-300 \% \text { dari kebutuhan rata -rata. }\end{array}$} \\
\hline
\end{tabular}


Tabel 2. Perhitungan Debit dan Faktor Jam Puncak DMA Tejosari

\begin{tabular}{|c|c|c|c|c|c|c|c|c|c|c|c|c|c|c|c|}
\hline Jam & $\begin{array}{l}\text { Hari } \\
\text { Pertama }\end{array}$ & $\%$ & $\begin{array}{l}\text { Hari } \\
\text { Kedua }\end{array}$ & $\%$ & $\begin{array}{l}\text { Hari } \\
\text { Ketiga }\end{array}$ & $\%$ & $\begin{array}{l}\text { Hari } \\
\text { Keempat }\end{array}$ & $\%$ & $\begin{array}{l}\text { Hari } \\
\text { Kelima }\end{array}$ & $\%$ & $\begin{array}{l}\text { Hari } \\
\text { Keenam }\end{array}$ & $\%$ & $\begin{array}{l}\text { Hari } \\
\text { Ketujuh }\end{array}$ & $\%$ & $\begin{array}{l}\text { Debit } \\
\text { rata-rata } \\
\text { per jam }\end{array}$ \\
\hline 22.00 & 94,4 & $32 \%$ & 81,9 & $33 \%$ & 55,8 & $20 \%$ & 71,1 & $24 \%$ & 53,6 & $22 \%$ & 71,1 & $30 \%$ & 69,4 & $20 \%$ & 71,1 \\
\hline 01.00 & 35,6 & $12 \%$ & 60,6 & $24 \%$ & 32,5 & $12 \%$ & 28,1 & $9 \%$ & 17,5 & $7 \%$ & 17,2 & $7 \%$ & 74,2 & $21 \%$ & 37,9 \\
\hline 04.00 & 63,6 & $21 \%$ & 46,9 & $19 \%$ & 58,6 & $21 \%$ & 50,0 & $17 \%$ & 30,3 & $12 \%$ & 37,5 & $16 \%$ & 48,6 & $14 \%$ & 47,9 \\
\hline 07.00 & 28,6 & $10 \%$ & 8,6 & $11 \%$ & 66,7 & $100 \%$ & 59,2 & $20 \%$ & 78,9 & $32 \%$ & 47,8 & $20 \%$ & 79,7 & $23 \%$ & 52,8 \\
\hline 10.00 & 77,2 & $26 \%$ & 51,9 & $21 \%$ & 65,3 & $23 \%$ & 93,3 & $31 \%$ & 65,6 & $27 \%$ & 65,3 & $27 \%$ & 80,3 & $23 \%$ & 71,3 \\
\hline $\begin{array}{l}\text { Debit } \\
\text { Total } \\
\end{array}$ & 299,4 & & 250,0 & & 278,9 & & 301,7 & & 245,8 & & 238,9 & & 352,2 & & 281 \\
\hline $\begin{array}{l}\text { Debit } \\
\text { Rata- } \\
\text { Rata }\end{array}$ & 59,9 & & 50,0 & & 55,8 & & 60,3 & & 49,2 & & 47,8 & & 70,4 & & 56,20 \\
\hline $\begin{array}{l}\text { Debit } \\
\text { Jam } \\
\text { Puncak }\end{array}$ & 94,4 & & 81,9 & & 66,7 & & 93,3 & &, 9 & & 71,1 & & 80,3 & & 71,30 \\
\hline $\begin{array}{l}\text { Faktor } \\
\text { Jam } \\
\text { Puncak }\end{array}$ & 1,58 & & 1,64 & & 1,20 & & 1,55 & & 1,60 & & 1,49 & & 1,14 & & 1,27 \\
\hline
\end{tabular}

Tabel 3. Perhitungan Debit dan Faktor Jam Puncak DMA Mega Bukit Mas

\begin{tabular}{|c|c|c|c|c|c|c|c|c|c|c|c|c|c|c|c|}
\hline Jam & $\begin{array}{l}\text { Hari } \\
\text { Pertama }\end{array}$ & $\%$ & $\begin{array}{l}\text { Hari } \\
\text { Kedua }\end{array}$ & $\%$ & $\begin{array}{l}\text { Hari } \\
\text { Ketiga }\end{array}$ & $\%$ & $\begin{array}{l}\text { Hari } \\
\text { Keempat }\end{array}$ & $\%$ & $\begin{array}{l}\text { Hari } \\
\text { Kelima }\end{array}$ & $\%$ & $\begin{array}{l}\text { Hari } \\
\text { Keenam }\end{array}$ & $\%$ & $\begin{array}{l}\text { Hari } \\
\text { Ketujuh }\end{array}$ & $\%$ & $\begin{array}{l}\text { Debit } \\
\text { rata- } \\
\text { rata } \\
\text { per jam }\end{array}$ \\
\hline 22.00 & 156,7 & $14 \%$ & 569,2 & $34 \%$ & 417,2 & $29 \%$ & 547,5 & $31 \%$ & 505,0 & $33 \%$ & 563,1 & $28 \%$ & 701,1 & $34 \%$ & 494,2 \\
\hline 01.00 & 302,0 & $27 \%$ & 349,7 & $21 \%$ & 280,0 & $19 \%$ & 417,8 & $24 \%$ & 243,1 & $16 \%$ & 239,7 & $12 \%$ & 225,8 & $11 \%$ & 294,0 \\
\hline 04.00 & 331,9 & $30 \%$ & 378,9 & $22 \%$ & 362,5 & $25 \%$ & 127,2 & $7 \%$ & 328,1 & $22 \%$ & 357,2 & $18 \%$ & 313,1 & $15 \%$ & 314,1 \\
\hline 07.00 & 89,4 & $8 \%$ & 151,4 & $27 \%$ & 148,3 & $36 \%$ & 442,2 & $25 \%$ & 168,3 & $11 \%$ & 485,6 & $24 \%$ & 521,0 & $25 \%$ & 286,6 \\
\hline 10.00 & 221,1 & $20 \%$ & 241,7 & $14 \%$ & 250,8 & $17 \%$ & 216,4 & $12 \%$ & 268,6 & $18 \%$ & 386,9 & $19 \%$ & 322,0 & $15 \%$ & 272,5 \\
\hline $\begin{array}{l}\text { Debit } \\
\text { Total }\end{array}$ & 1101,2 & & 1690,8 & & 1458,9 & & 1751,1 & & 1513,1 & & 2032,5 & & 2083,0 & & 1662 \\
\hline
\end{tabular}


ISSN 2550-0023

\begin{tabular}{|c|c|c|c|c|c|c|c|c|c|c|c|c|}
\hline Jam & $\begin{array}{l}\text { Hari } \\
\text { Pertama }\end{array}$ & $\%$ & $\begin{array}{l}\text { Hari } \\
\text { Kedua }\end{array}$ & $\%$ & $\begin{array}{l}\text { Hari } \\
\text { Ketiga }\end{array}$ & $\%$ & $\begin{array}{l}\text { Hari } \\
\text { Keempat }\end{array}$ & $\begin{array}{l}\text { Hari } \\
\text { Kelima }\end{array}$ & $\%$ & $\begin{array}{l}\text { Hari } \\
\text { Keenam }\end{array}$ & $\begin{array}{ll}\text { Hari } & \% \\
\text { Ketujuh } & \end{array}$ & $\begin{array}{l}\text { Debit } \\
\text { rata- }\end{array}$ \\
\hline $\begin{array}{l}\text { Debit } \\
\text { Rata- } \\
\text { Rata }\end{array}$ & 220,2 & & 338,2 & & 291,8 & & 350,2 & 302,6 & & 406,5 & 416,6 & 332,30 \\
\hline $\begin{array}{l}\text { Debit } \\
\text { Jam } \\
\text { Puncak }\end{array}$ & 302,0 & & 569,2 & & 417,2 & & 547,5 & 505 & & 563,1 & 701,1 & 494,25 \\
\hline $\begin{array}{l}\text { Faktor } \\
\text { Jam } \\
\text { Puncak }\end{array}$ & 1,37 & & 1,68 & & 1,43 & & 1,56 & 1,67 & & 1,39 & 1,68 & 1,49 \\
\hline
\end{tabular}

Tabel 2 dan 3 merupakan hasil perhitungan debit dan faktor jam puncak DMA Tejosari dan DMA Mega Bukit Mas. Berikut adalah perhitungan faktor jam puncak DMA Tejosari:Tabel 2 dan 3 merupakan hasil perhitungan debit dan faktor jam puncak DMA Tejosari dan DMA Mega Bukit Mas. Berikut adalah perhitungan faktor jam puncak DMA Tejosari:

$$
\begin{aligned}
\text { Faktor Jam Puncak } & =\frac{\text { Debit Jam Puncak }}{\text { Debit Rata }- \text { Rata }} \\
=\frac{81,9}{50} & =1,64
\end{aligned}
$$

Setelah didapatkan hasil faktor jam puncak DMA Tejosari adalah 1,64. Perhitungan yang sama juga dilakukan pada DMA Mega Bukit Mas, maka didapatkan faktor jam puncak untuk DMA Mega Bukit Mas sebesar 1,68 . Setelah mengetahui faktor jam puncak, maka selanjutnya yaitu menghitung faktor harian maksimum dengan membagi antara debit maksimum selama tujuh periode pembacaan meter induk dengan debitrata-rata selama tujuh periode. Berikut adalah contoh perhitungan untuk DMA Tejosari:
Faktor Harian Maksimum $=\frac{\text { Debit Maksimum }}{\text { Debit Rata }- \text { Rata }}=\frac{352,2}{281}=1,25$

Hasil faktor maksimum untuk kedua DMA yaitu sama, sebesar 1,25, yang membedakan antara DMA Tejosari dan DMA Mega Bukit Mas adalah pada faktor jam puncak. Hal ini dikarenakan faktor peak dipengaruhi oleh jumlah penduduk, dimanasemakin tinggi jumlah penduduk, maka faktor peak akan menurun (Juwana,2000). Selain itu, berdasarkan data PDAM Tirta Moedal Kota Semarang tahun 2017, DMA Mega Bukit Mas memiliki kehilangan air yang lebih tinggi daripada DMA Tejosari. Menurut Juwana (2000) kehilangan air yang tinggi mengakibatkan tingginya faktor peak karena mempengaruhi suplai air ke konsumen, sehingga memicu tejadinya lonjakan pada saat-saat tetentu.

Pembacaan meter induk berguna untuk mengetahui pola pemakaian air, sehingga didapatkan data fluktuasi debit dalam sehari. Pola pemakaian air tersebut dapat digunakan untuk mengetahui seberapa besar debit yang dibutuhkan oleh konsumen DMA Tejosari dan DMA Mega Bukit Mas. (Khotimah, 2017) Berikut adalah perhitungan pola pemakaian air kedua DMA. 
:Tabel 4. Pola Pemakaian Air DMA Tejosari dan DMA Mega Bukit Mas

\begin{tabular}{|c|c|c|c|c|c|c|}
\hline Jam & $\begin{array}{lr}\text { Debit } & \text { Harian } \\
\text { Maksimum } & \text { DMA } \\
\text { Tejosari } & \end{array}$ & $\%$ & Pattern & $\begin{array}{lr}\text { Debit } & \text { Harian } \\
\text { Maksimum DMA } & \text { Mega Bukit Mas }\end{array}$ & $\%$ & Pattern \\
\hline 22.00 & 71,1 & 25,29 & 1,26 & 494,2 & 29,75 & 1,49 \\
\hline 01.00 & 37,9 & 13,50 & 0,68 & 294,0 & 17,70 & 0,88 \\
\hline 04.00 & 47,9 & 17,06 & 0,85 & 314,1 & 18,91 & 0,95 \\
\hline 07.00 & 52,8 & 18,78 & 0,94 & 286,6 & 17,25 & 0,86 \\
\hline 10.00 & 71,3 & 25,36 & 1,27 & 272,5 & 16,40 & 0,82 \\
\hline $\begin{array}{l}\text { Debit } \\
\text { Total } \\
\end{array}$ & 280,99 & \multirow{4}{*}{\multicolumn{2}{|c|}{100}} & 1661,51 & \multirow{4}{*}{100} & \\
\hline $\begin{array}{l}\text { Debit } \\
\text { Rata- } \\
\text { Rata } \\
\end{array}$ & 56,20 & & & 332,30 & & \\
\hline $\begin{array}{l}\text { Debit Jam } \\
\text { Puncak }\end{array}$ & 71,30 & & & 494,20 & & \\
\hline $\begin{array}{l}\text { Pattern } \\
\text { Maksimal }\end{array}$ & 1,27 & & & 1,49 & & \\
\hline $\begin{array}{l}\text { Telah } \\
\text { fluktuasi pe } \\
\text { digunakan ur } \\
\text { bak penam } \\
\text { langkah sel } \\
\text { selisih air } \\
\text { pemakaian } \\
\text { Mega Bukit } \\
\text { selama } 15 \mathrm{j} \\
\text { didapat dari } \\
15 \text { jam, berik } \\
\text { Pemakai }\end{array}$ & $\begin{array}{l}\text { likatakan di atas } \\
\text { makaian air bers } \\
\text { ttuk menghitung kap } \\
\text { oung atau reserv } \\
\text { anjutnya adalah m } \\
\text { antarapengaliran } \\
\text { air. DMA Tejosari } \\
\text { Mas mendapatkan j } \\
\text { am, maka \% penga } \\
\text { data pengambilan } \\
\text { ut contoh perhitunga } \\
\text { an air dalam satu ha }\end{array}$ & $\begin{array}{l}\text { bahwa } \\
\text { ih dapat } \\
\text { asitas dari } \\
\text { ir, maka } \\
\text { enentukan } \\
\text { dengan } \\
\text { dan DMA } \\
\text { atah aliran } \\
\text { mbilan air } \\
\text { air selama } \\
\text { nnya: } \\
\text { ri (15 jam) }\end{array}$ & & 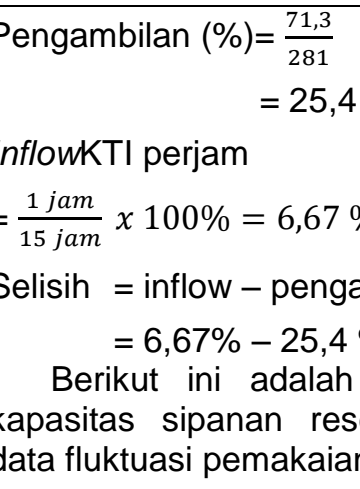 & $\begin{array}{l}\% \\
\text { ambilan } \\
\%=-18 \\
\text { hasil } \\
\text { ervoir } \\
\text { n air DN }\end{array}$ & $\begin{array}{l}73 \% \\
\text { perhitungan } \\
\text { erdasarkan } \\
\text { A Tejosari. }\end{array}$ \\
\hline
\end{tabular}
dianggap $100 \%$,

Tabel 5. Perhitungan Kapasitas Simpanan Reservoir DMA Tejosari

\begin{tabular}{|c|c|c|c|c|c|}
\hline Jam & $\begin{array}{l}\text { Debit } \\
\left(\mathrm{m}^{3} / \mathrm{jam}\right)\end{array}$ & $\%$ & Inflow (\%) & Selisih & Akumulatif \\
\hline 22.00 & 71,1 & 25,29 & 17,6 & $-7,6$ & $-7,6$ \\
\hline 01.00 & 37,9 & 13,50 & 17,6 & 4,1 & $-3,5$ \\
\hline 04.00 & 47,9 & 17,06 & 17,6 & 0,6 & $-2,9$ \\
\hline 07.00 & 52,8 & 18,78 & 17,6 & $-1,1$ & $-4,0$ \\
\hline 10.00 & 71,3 & 25,36 & 17,6 & $-7,7$ & $-11,8$ \\
\hline Debit Total & 280,99 & 100,00 & 88,2 & $-11,8$ & $-29,9$ \\
\hline $\begin{array}{l}\text { Debit Rata- } \\
\text { Rata }\end{array}$ & 56,20 & 20 & 17,6 & $-2,4$ & $-6,0$ \\
\hline$Q$ day max & 71,30 & 25,36 & 17,6 & 4,15 & $-2,9$ \\
\hline & & & & $-7,7$ & \\
\hline$Q$ day $\min$ & 37,90 & 13,50 & 17,6 & & $-11,8$ \\
\hline
\end{tabular}


Faktor pengali kebutuhan reservoir

$=\%$ akumulatif air maks $+\%$ akumulatif min $=2,9 \%+11,8 \%$

$=14,7 \%$

Perhitungan kebutuhan reservoir dijabarkan sebagai berikut:

1. Kebutuhan harian maksimum adalah $1711,2 \mathrm{~m}^{3} /$ hari

2. (A) Penyimpanan penyeimbang jam puncak untuk daerah pelayanan Desa Sumberwungu dan Giripanggung adalah $14,7 \% \quad x 1711,2 \mathrm{~m}^{3} /$ hari $=251,5$ $\mathrm{m}^{3}$

3. (B) Volume kebutuhan air hidran kebakaran selama 45 menit (SNI)

Jumlah probabilitas 3 buah hidran kebakaran secara bersamaan yaitu : $31 \mathrm{l} / \mathrm{s} \times 2700 \mathrm{~s} \times 3$ buah $=251,1 \mathrm{~m}^{3}$

4. (C) Penyimpanandarurat $=25 \% \mathrm{x}$ $(A+B)=125,65 \mathrm{~m}^{3}$

5. Volume total reservoir yang dibutuhkanyaitu $A+B+C=628,25 \mathrm{~m}^{3}$

Dari perhitungan diatas dapat diketahui bahwa volume reservoir yang dibutuhkan untuk DMA Tejosari sebesar 628,25 $\mathrm{m}^{3}$.

\section{Kesimpulan}

Hasil penelitian ini didapatkan bahwa faktor harian maksimum DMA Tejosari lebih rendah dibandingkan DMA Mega Bukit Mas, yaitu 1,64 dan 1,68. Hal ini disebabkan jumlah penduduk DMA Mega Mega Bukit Mas lebih sedikit dibandingkan DMA Tejosari. Penyebab lainnya yaitu tingkat kehilangan air di DMA Mega Bukit Mas memiliki nilai lebih tinggi. Sehingga dapat disimpulkan bahwa faktor jam puncak diperngaruhi oleh jumlah penduduk dan tingkat kehilangan air.

\section{Daftar Pustaka}

Juwana,W. 2000. Analisis Fluktuasi Pemakaian Air dan Faktor Peak
Pulau Batam, Intstitut Teknologi Bandung, Bandung.

Hidayat, I.N. dkk. 2014. Analisis Kebutuhan Air Berdasarkan Fluktuasi Pemakaian Air, Semarang.

Mangkoedihardjo, S.dan Ganjar Samudro. 2012. Evaluasi dan Kebutuhan Air Minum, Guna Widya,Surabaya.

Arsad Siregar, Nikmad., dan Ahmad Perwira Mulia. 2013 . Evaluasi Kehilangan Air (Water Losses) PDAM Tirtanadi Padangsidimpuan di Kecamatan Padangsidimpuan Selatan, Medan.

Syahputra, B. 2018. Penentuan Faktor Jam Puncak dan Harian Maksimum Terhadap Pola Pemakaian Air Domestik di Kecamatan Kalasan, Sleman, Yogyakarta., Yogyakarta.

Bersih untuk Kecamatan Kubu Kabupaten Karangasem.

Saparina, W. 2017. Penurunan Kehilangan Airdi Sistem Distribusi Air Minum PDAM Kota Malang. Surabaya.

Peraturan Menteri Pekerjaan Umum Nomor: 18. 2007. Penyelenggaraan Pengembangan Sistem Penyediaan Air Minum.

Jujubandung. 2012. Jujubandung Blog Bebas. Diakses tanggal 11 Juli 2018, dari

https://jujubandung.wordpress.com/2 012/06/02/kebutuhan-air-minum-diwilayah-perencanaan-studi-kasus/

Khotimah, C.K. 2017. Evaluasi Transmisi dan Distribusi Sub. Sistem Bribin PDAM Tirta Handayani Kabupaten Gunungkidul Unit Reservoir Pelayanan R5 Desa Sumberwungu dan Giripanggung. UNDIP, Departemen Teknik Lingkungan, Laporan Kerja Praktik. Semarang: UNDIP.

Hidayat, Muhammad Alvan, dkk. 2013. Studi Perencanaan Sistem Penyediaan 